\title{
Web of Science
}

1 Clarivate

Analytics

\section{Slippage Detection for Grasping Force Control of Robotic Hand Using Force Sensing Resistors}

By: Farag, M (Farag, Mohannad) ${ }^{[1]}$; Azlan, NZ (Azlan, Norsinnira Zainul) ${ }^{[2]}$; Alsibai, MH (Alsibai, Mohammed Hayyan) ${ }^{[3]}$; Abd Ghafar, AN (Abd Ghafar, Abdul Nasir) [1]

\section{PROCEEDINGS OF THE 2019 5TH INTERNATIONAL CONFERENCE ON COMPUTER AND TECHNOLOGY APPLICATIONS (ICCTA} 2019)

Book Group Author(s): ACM

Pages: $98-102$

DOI: $10.1145 / 3323933.3324077$

Published: 2019

Document Type: Proceedings Paper

\section{Conference}

Conference: 5th International Conference on Computer and Technology Applications (ICCTA)

Location: Istanbul, TURKEY

Date: APR 16-17, 2019

Sponsor(s): Gazi Univ

\section{Abstract}

This paper presents the formulation of a nonlinear adaptive back stepping force control in grasping weight-varying objects using robotic hand driven by Pneumatic Artificial Muscle (PAM). The modelling and control problems arise from the high nonlinear PAM dynamics and the inherent hysteresis leading to a lack of robustness in the hand's performance. The robotic finger and the PAM actuator been mathematically modelled as a nonlinear second order system based on an empirical approach. An adaptive backstepping controller has been designed for force control of the pneumatic hand. The estimator of the system uncertainty is incorporated into the proposed control law and a slip detection strategy is introduced to grasp objects with changing weights. The simulation and experimental results show that the robotic hand can maintain grasping an object and stop further slippage when its weight is increased up to $500 \mathrm{~g}$ by detecting the slip signal from the force sensor. The results also have proven that the adaptive backstepping controller is capable to compensate the uncertain coulomb friction force of PAM actuator with maximum hysteresis error 0.18 degrees.

\section{Keywords}

Author Keywords: robotic hand; force control; object slip detection; pneumatic muscle; adaptive backstepping KeyWords Plus: ARTIFICIAL MUSCLE; SYSTEM; TACTILE

\section{Author Information}

Reprint Address: Farag, M (reprint author)

+ Univ Malaysia Pahang, Fac Engn Technol, Pahang, Malaysia.

Addresses:

+ [1] Univ Malaysia Pahang, Fac Engn Technol, Pahang, Malaysia

+ [2] Int Islamic Univ Malaysia, Dept Mechatron Engn, Kuala Lumpur, Malaysia

[ 3 ] Int Univ Sci \& Technol, Fac Engn \& Technol, Damascus, Syria

E-mail Addresses: mohanadfaraj@gmail.com; sinnira@iium.edu.my; mhdhayyan@gmail.com; abdnasir@ump.edu.my

Funding

\begin{tabular}{|l|l|}
\hline Funding Agency & Grant Number \\
\hline University Malaysia PAHANG & $\begin{array}{l}\text { RDU } 1703284 \\
\text { PGRS190359 }\end{array}$ \\
\hline
\end{tabular}

View funding text

Publisher

\section{Citation Network}

In Web of Science Core Collection

0

Times Cited

Create Citation Alert

\section{1}

Cited References

View Related Records

\section{Use in Web of Science}

Web of Science Usage Count

1

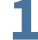

Last 180 Days Since 2013

Learn more

This record is from

Web of Science Core Collection

- Conference Proceedings Citation Index-

Science

Suggest a correction

If you would like to improve the quality of the data in this record, please suggest a correction. 


\section{Categories / Classification}

Research Areas: Computer Science; Engineering

Web of Science Categories: Computer Science, Theory \& Methods; Engineering, Electrical \& Electronic

\section{See more data fields}

\section{Cited References: 31}

1. Direction of Slip Detection for Adaptive Grasp Force Control with a Dexterous Robotic Hand

By: Abd, Moaed A.; Gonzalez, Iker J.; Colestock, Thomas C.; et al.

2018 IEEE/ASME INTERNATIONAL CONFERENCE ON ADVANCED INTELLIGENT MECHATRONICS (AIM) Book Series: IEEE ASME International Conference on Advanced Intelligent Mechatronics Pages: 21-27 Published: 2018

2. Hands for dexterous manipulation and robust grasping: A difficult road toward simplicity

Times Cited: 446

By: Bicchi, A

IEEE TRANSACTIONS ON ROBOTICS AND AUTOMATION Volume: 16 Issue: 6 Pages: $652-662$ Published: DEC 2000

3. Fuzzy enhanced control of an underactuated finger sing tactile and position sensors

Times Cited: 20

By: Birglen, L; Gosselin, CM

2005 IEEE INTERNATIONAL CONFERENCE ON ROBOTICS AND AUTOMATION (ICRA), VOLS 1-4 Book Series: IEEE International Conference on Robotics and Automation ICRA Pages: 2320-2325 Published: 2005

4. Title: [not available]

Times Cited: 51

By: Birglen, L.; Lalibert`e, T.; Gosselin, C.

Underactuated Robotic Hands Volume: 40 Published: 2008

Publisher: Springer

5. Nonlinear control of a pneumatic muscle actuator: Backstepping vs. sliding-mode

Times Cited: 71

By: Carbonell, P; Jiang, ZP; Repperger, DW

PROCEEDINGS OF THE 2001 IEEE INTERNATIONAL CONFERENCE ON CONTROL APPLICATIONS (CCA'01) Pages: 167-172 Published: 2001

6. Human grasp choice and robotic grasp analysis

Times Cited: 42

By: Cutkosky, M. R.; Howe, R. D

Dextrous Robot Hands Pages: 5-31 Published: 1990

New York

Publisher: Springer, New York, NY, USA

7. Adaptive Backstepping Position Control of Pneumatic Anthropomorphic Robotic Hand

Times Cited: 3

By: Farag, Mohannad; Azlan, Norsinnira Zainul

2015 IEEE INTERNATIONAL SYMPOSIUM ON ROBOTICS AND INTELLIGENT SENSORS (IEEE IRIS2015) Book Series: Procedia Computer Science Volume: 76 Pages: 161-167 Published: 2015

8. Title: [not available]

Times Cited: 1

By: Farag, Mohannad.

Adaptive Backstepping Control of Pneumatic Anthropo-morphic Hand Published: 2016

Publisher: M. S. International Islamic University Malaysia

9. Development of Anthropomorphic Robotic Hand Driven by Pneumatic Artificial Muscles for robotic applications 